\title{
MUJERES DEPORTISTAS ESPAÑOLAS: ESTEREOTIPOS DE GÉNERO EN LOS MEDIOS DE COMUNICACIÓN
}

\author{
SPANISH FEMALE ATHLETES: \\ GENDER STEREOTYPES IN THE MEDIA
}

Elena López Albalá

Universidad de Alicante (España)

albala@gmail.com

\section{Resumen}

En el campo científico, numerosos estudios han analizado la presencia y representación de las mujeres en los medios de comunicación. En todos ellos se ha podido comprobar que existe un sesgo de género muy pronunciado tanto en el número de noticias que se publican como en la forma de representarlas. La escasa visibilidad de las mujeres en la prensa se observa en todos los ámbitos, también en el deportivo. En este trabajo se exponen los principales resultados de una investigación en la que se analizan las noticias que recoge la prensa deportiva sobre el deporte femenino entre el 1 de febrero de 2015 y el 1 de febrero de 2016. La principal conclusión es que la prensa deportiva ignora el deporte femenino ${ }^{1}$.

Palabras clave: medios de comunicación; periodismo deportivo; género; mujer deportista; sexismo; estereotipos.

\footnotetext{
${ }^{1}$ El presente artículo es producto del Trabajo Final de Grado realizado por la autora y tutelado por la profesora María José González-Río.
} 


\section{Abstract}

The media publications are an important source of information contributing to the selection of the news that are made and the way these are exposed to the configuration of values, cultural habits, and "social imaginary" for the population as a whole (Theory of agenda-setting).

In the scientific realm, numerous studies have analysed the presence and representation of women in the media. In all of them it has been verified that there is a gender bias which is very pronounced in both, the number of news that are published and the form of representing them. The low visibility of women in the press was observed in all areas; also in sports. Precisely, this paper presents the main results of a research that analyses the news published by the sports media about women's sport. It is intended to put in evidence how the national sports press represents female elite athletes, the competitions in which they participate, their successes etc.; in a period of time that ranges from 1 February 2015 to 1 February 2016. With this purpose, different female sporting events were collected from various sports publications, web pages, etc. At the same time these events were searched in the main sports publications in Spain (on the same dates) to verify if these news were echoed or not, and if so, how this was made. The newspapers selected were the As, Marca, Mundo Deportivo and the Sport; all of them owned by different corporate groups with a greater number of readers and a broad social impact.

The main conclusion that can be drawn from this work is that sports media ignores women's sport. News about the successes of the Spanish athletes in different disciplines rarely appear in the media publications; neither in those which are traditionally considered as female nor in those accepted as male ones.

Key words: media, sports journalism, gender, woman, sport, sexism, stereotypes.

\section{Extended abstract}

The research is theoretically based on the Agenda-setting theory. McCombs and Shaw (1972) were the first authors test this theory in a study carried out during the United States presidential elections in 1968 (Canel, 1999:188). The results of this research allowed the authors to affirm the existence of an important relation between the issues that the media considered important and those considered important by the public.

The media are an important source of information, and selection of the news produced and the way they are posed contribute to the configuration of values, cultural habits, and "social imaginary" for the population as a whole (Agendasetting Theory). Thanks to this theory, it is possible to specify the scope of the media in the way individuals view political and public affairs. The media are 
able to convey an interpretation that becomes the same for an important part of society. The greater the weight the media give the news, the greater the relevance will be among readers. In fact, the agenda-setting theory explains the transference of relevance of the images of the world transmitted by the media to the images in the head of those who expose themselves to them (MaCombs, 2006: 135).

McCombs and Evatt (1995) developed a second level of the theory in which they established that the media not only manage to influence the subjects which people think about, but also how they think about them.

Subsequent research has explained on which type of people the influence of the media is greater as well as the role played by the directors of the media, editorial boards, and other media, in the choice of relevant topics that occupy the front pages of newspapers, editorials, or time allocated on the television news.

In the scientific field, numerous studies have analyzed the presence and representation of women in the media. Also, although such research combines different subjects and points of view, it is possible to find common consensus on topics such as the unequal social projection of athletes, educational values of sport, the social function of the mass media in general, and sports in particular, sexist stereotypes in sport and sports journalism, and sport as an almost exclusively masculine area.

In all of the studies, it has been verified that there is a very pronounced gender bias in the number of news items that are published as well as the way they in which they are represented. The low visibility of women in the press can be observed in all areas; also in sport.

Due to the substantial increase in the number of women dedicated professionally to sport and new technologies, it was thought that gender equality would be reached. However, the gap between the sexes remains remarkably high. With the increase in the amount of information on sporting events, the balance has remained in favor of the male gender, so women's sports continue to be underrepresented even today. In addition to this, the existence of a series of stereotypes based on unreal models in which the roles played by women in this field are characterized by appearing both as women provoking desire and as passive women. They rarely get to play the active role of a protagonist.

There is a tendency to follow social standards, to accept the stereotypes established in all areas and, with gender, the same thing happens. Individuals are prone

to manifest behaviors based on gender schemas; therefore, boys and girls tend to behave in a similar way to those of their own sex. In reality, what happens is that they pay more attention to the activities of "their peers".

It should be noted that not all sports enjoy the same media impact and that practicing a sport is not the same as consuming it. In other words, it is 
necessary to make a distinction between a sport that is practiced and one that is followed through the media. This distinction further increases the gender imbalance. An example of this can be seen in the effects of economic profitability in society in general, the media, and in sport. Thus, the lack of important sponsors in women's sport involves a lack of economic profitability and, consequently, it is rarely covered by the media.

The reification of gender inequality in the world of sport is very evident. Athletes become advertisements for products of all kinds, including products not connected with sports. Cosmetics and clothing are the most popular products. Unlike with men, advertising does not usually feature sportswomen, except for a few sports stars, because they are barely known among the majority of the target audience. Thus, media and advertising have turned male athletes into both sports idols and social referents that people follow from a very early age.

The above occurs in a particular way in the so-called "king of sports" in Spain: football. It is well known that football occupies the front pages of newspapers and magazines and has the most coverage on television, with many news and sports programs devoted almost exclusively to the sport. Popular radio stations dedicate practically all their sports programming to the men's football, to the extent that Saturday and Sunday afternoons are practically entirely dedicated to the Spanish and European men's football.

This paper presents the results of a research that analyzes the news gathered in the sports media on women's sport. It intends to show how the national sports press represented elite female athletes, the competitions in which they participated, and their successes, between 1 February 2015 and 1 February 2016. To this end, coverage of female sporting events was gathered from various online and offline sports publications and then it was checked if, and how, they were covered by the Spanish sports press. The newspapers selected were the As, Marca, Mundo Deportivo and the Sport, all belonging to different business groups, with a large readership and a broad social impact.

The main conclusion that can be drawn from the results is that the sports media ignore women's sport. News about the successes of Spanish athletes in diverse sporting disciplines rarely appear in the press, both those that are considered traditionally feminine and masculine.

\section{INTRODUCCIÓN}

Los medios de comunicación de masas son una herramienta fundamental en la sociedad actual ya que desempeñan una importante labor de socialización; se encargan de la transmisión e integración de valores, normas de comportamiento, así como de la creación de referentes para la sociedad. 
Desde hace algún tiempo, el mundo deportivo masculino es un caldo de cultivo de referentes para la sociedad, haciendo que deportistas como Cristiano Ronaldo, Gareth Bale, Rafa Nadal o Marc Márquez sean imitados en su corte de pelo, en su forma de vestir, de hablar etc. De alguna manera, los medios de comunicación se encargan de mostrarnos y crear una "realidad" y ahí es donde entra en juego el papel de los estereotipos.

La acción de estereotipar es la de fijar de manera permanente y de identificar lo estereotipado como el seguimiento de un modelo preestablecido, conocido y formalizado que se adopta de una manera fija. Podríamos aventurar que los medios de comunicación tienden a reproducir y a difundir los estereotipos sociales sin cuestionarlos previamente. (Bach Arús et al., 2000:44).

Numerosos estudios han podido demostrar que en los medios de comunicación existe un sesgo de género muy pronunciado. Este se hace visible en el número de noticias que publican, el lugar que ocupan dentro del periódico, el tiempo que se les dedica en la televisión o en la radio, el trato que reciben y también, qué se dice de ellas y ellos, así como los distintos calificativos que se usan.

En este trabajo, a través de un análisis de contenido de la prensa deportiva digital española, se pretende comprobar si los periódicos deportivos recogen noticias sobre el deporte femenino. Hasta qué punto el número de noticias que publican es equiparable a las noticias sobre deporte masculino. Además, también interesa analizar el contenido de las noticias para comprobar si los estereotipos de género siguen o no estando presentes. Finalmente, se pretende explorar las repercusiones que puede tener sobre la sociedad el tratamiento que realizan los periódicos de las noticias sobre el deporte femenino ya que, tal como plantea la teoría de la agenda-seting, desarrollada en el apartado siguiente, cuanta más importancia de un medio de comunicación a un tema (agenda de los medios), más importancia le dará el público (agenda del pública) (Lucas, 1999:248).

En el ámbito de la comunicación de masas existe una amplia literatura que demuestra la influencia que ejercen las noticias en la configuración de las imágenes que nos formamos del mundo. En este trabajo se parte del hecho de que la prensa es una importante fuente de información que contribuye con la selección de las noticias que se realizan y la forma de plantearlas, a la configuración de "imaginarios sociales" sobre el deporte femenino y las deportistas para el conjunto de la población. Para poder comprender un poco mejor el tema a tratar, se asentarán unas bases según la teoría de la agendasetting y en los trabajos pioneros de Lippmann (1922).

Lippmann fue el primer autor que planteó la influencia que ejercen los medios de comunicación en los ciudadanos. Este autor señaló el papel que desempeñan los medios al definir todo nuestro mundo, más allá de los asuntos que conciernen al entorno inmediato. La información que proporcionan desempeña un papel crucial en la construcción de las imágenes que el público 
se forma de la realidad. Por otra parte, aunque los medios publican información sobre gran cantidad de temas, las personas no disponen del tiempo necesario para formarse una opinión sobre cada uno de ellos. Entre todo lo que se publica, la gente se interesa por un número limitado y es sobre esos temas a los que el público presta atención sobre el que se produce el efecto fijación de agenda (DeFleur y Ball-Rokeach 1982:325).

Sobre esta base, McCombs y Shaw en 1972 elaboraron la teoría de la agendasetting. La teoría explica la influencia que ejercen las noticias sobre las imágenes que nos formamos del mundo. La agenda-setting, postula la capacidad de los medios para estructurar las opiniones de la audiencia y producir cambios en las opiniones preexistentes. En ella se establece efectos de carácter cognitivo, poderosos, directos, aunque no inmediatos, sobre el público. Además, los elementos destacados en la imagen que dan los medios de comunicación se vuelven destacados en la imagen que se hace la audiencia. Esta teoría dibuja un mapa muy detallado de la contribución de la comunicación de masas a las imágenes que nos hacemos de los asuntos públicos. McCombs y Shaw la definen como la "habilidad de los mass media para estructurar las opiniones de la audiencia y producir cambios entre las opiniones ya existentes". (McCombs y Shaw, 1992:279). De este modo, esta teoría descansa sobre la base de que cuanta más importancia de un medio de comunicación a un tema (agenda de los medios), más importancia le dará el público (agenda del pública) (Lucas, 1999:248) y no sólo esto, sino que también condicionará la manera de verlo (McCombs, 2006).

Además del medio, los efectos sobre el público están condicionados por las características individuales de la audiencia. De hecho, no todas las personas responden del mismo modo a la información que transmiten los medios (DeFleur y Ball-Rokeach 1982:325). No obstante, "Para demostrar concluyentemente y documentar la existencia de un efecto mediático como el del establecimiento de agenda, los investigadores deben reunir evidencia diversa, que incluye el contenido, la exposición, el efecto y las circunstancias" (Kosicki, 1993).

Pero para que el presente estudio posea un carácter más completo, es necesario abordar también las teorías de género. La categoría género-mujer es un constructo social al cual se le atribuyen cualidades o estereotipos. Este concepto de género se institucionaliza de manera más sólida en los 70’ cuando se introduce una nueva teoría feminista de comunicación (Feminist Media Studies). La teoría pretende poner en evidencia la realidad que viven las mujeres y denunciar el reducido número de noticias recogidas en los medios en las que ellas son protagonistas. Brenda Dervin, a finales de los 80, elaboró un nuevo enfoque feminista de la comunicación. Propuso aunar los significados, las estructuras y los actores sociales desde un paradigma constructivista. De hecho, se convirtió en una de las teorías más importantes en lo que respecta al género y los mass media. Para ella era necesario conocer las limitaciones, los 
pensamientos, las invenciones, etc., de las personas para poder conocer el verdadero alcance simbólico, o lo que es lo mismo, saber el nivel de representación de la sociedad.

¿Cómo se puede relacionar con el deporte? La categoría género no incluye una visión de la mujer diferente a la relacionada con la delicadeza o con la fragilidad. Por lo que la mujer deportista tiene y debe de tener un canon físico concreto, que no altere la imagen de mujer frágil. Así, el imaginario deportista de la mujer es muy diferente a la potencialidad física que pueda tener su cuerpo. También, es importante saber que, con mucha frecuencia, como se verá más adelante, los medios no recogen las noticias protagonizadas por mujeres deportistas y cuando lo hacen, a menudo las relegan a un segundo plano como acompañante de o como periodista-comentarista secundaria. Estos hechos tienen una repercusión importante dado que los medios de comunicación y especialmente la televisión son una pieza clave en el proceso de socialización. Con mucha frecuencia, transmiten una imagen de la mujer errónea que no concuerda con la imagen que tienen las propias mujeres y con lo que realmente han conseguido. "La televisión funciona bajo un modelo de comunicación basado en la exaltación de ciertos estereotipos y roles que han reducido la imagen de la mujer a modelos muy arbitrarios que no representan, las actuales prácticas de empoderamiento que están en los procesos de cambio como actores sociales" (Torres en Oyanedel Avilés, 2008:29). Los medios de comunicación no reparan en la imagen que puedan estar transmitiendo de las mujeres, su interés es vender su producto a la audiencia. "En la televisión se ha establecido o construido una relación completamente asimétrica de género [...] En este sentido, la televisión ha dejado de lado o directamente ha excluido el mundo de lo femenino, priorizando un enfoque patriarcal a través de los productos que de ella se genera" (Oyanedel Avilés, 2008:28).

Por tanto, además de la imagen cosificada que se le da a la mujer dentro de los medios de comunicación y en este caso que atañe, en el mundo deportivo, también hay que añadir el silencio o la ausencia de noticias de los logros alcanzados por ellas en este ámbito que es a lo que profesionalmente se dedica una mujer deportista. Sirva como ejemplo, las representaciones que hacen de la mujer los medios en las portadas o las imágenes de las gimnastas, jugadoras, atletas, etc., que salen en la prensa deportiva; de otra manera, no venden.

\section{EL DEPORTE MASCULINO Y FEMENINO EN LOS MEDIOS}

A lo largo de la historia el deporte (sobre todo la práctica profesional) se ha asociado al sexo masculino ya que, para el femenino, la práctica deportiva implicaba una pérdida de feminidad, un perjuicio para la salud o directamente, el pensamiento de una negación absoluta de aptitud, falta de interés, etc. De hecho, a principios del siglo XX, la medicina, sin otorgar argumentos científicos, ponían en previo aviso a las mujeres sobre la relación nociva que existía entre el 
deporte y la capacidad reproductiva, ya que una práctica extenuante de deporte podría acarrear daños irreparables en los órganos reproductivos, y por ello, dicha afirmación, alejó durante décadas a las mujeres de las pistas de atletismo y de los deportes de contacto (Vega, R., 2012).

Por el contrario, para los hombres, el deporte es una manera de afianzar y confirmar su masculinidad. Es un reconocimiento social a su hombría. Por eso, aunque no profundizaré sobre ello es frecuente escuchar que en deportes como el fútbol, rugby, baloncesto, boxeo, balonmano etc., no hay homosexuales. Es una manera de decir que quien practica algún deporte es "demasiado hombre" y por ello es imposible que un homosexual pueda "colarse"; hay una negación por parte del género masculino hacia esta posibilidad. $Y$ con respecto a la mujer, si se sale de los deportes "establecidos" para ellas como lo puede ser la gimnasia rítmica o el tenis, por ejemplo, entonces se pone en duda y se cuestiona su sexualidad. Tal y como se recoge en El sexo de la noticia,

Los comentarios radiofónicos o televisivos son a veces despectivos, e inciden reiteradamente sobre uno de los tópicos que pesan sobre el deporte practicado por mujeres: la virilización y la falta de atractivo. El mito de la virilización de las mujeres a través del deporte se ha convertido actualmente en un interés desmesurado por la sexualidad de las deportistas. A menudo se insinúa, cuando no se dice abiertamente, que tal o cual tenista es lesbiana. Por un lado, encontramos que el hecho de que las mujeres puedan hablar sin problemas de sus preferencias sexuales es un logro positivo, porque durante mucho tiempo ni se reconocía que las mujeres tuvieran una sexualidad propia. Ahora bien, la insistencia de los medios de comunicación en poner de relieve el lesbianismo de algunas deportistas contrasta mucho -en una nueva muestra de asimetría periodística- con la discreción con la que hablan de las preferencias eróticas de los hombres, sean deportistas o no. Una vez más, una muestra de un tratamiento diferenciado en función del género (Bach Arús, M. et al., 2000).

Con respecto a los estereotipos vigentes en la sociedad, una mujer que suda mucho o que posee unos músculos desarrollados, deja de ser femenina y como consecuencia, se aleja de los cánones establecidos para la mujer y pasa a la categoría de "macho", "marimacho", etc. Como es sabido, la fuerza, la resistencia, la potencia y la velocidad, son atributos casi exclusivamente masculinos. En los hombres se aprecia la musculatura, la potencia, mientras que por el contrario en las mujeres lo que se tiene en cuenta es la belleza, la esbeltez. Un ejemplo de ello puede ser la natación, en la que actualmente hay grandes referentes femeninos, como Jessica Vall, Mireia Belmonte o Melani Costa, pero sus cuerpos no son estéticamente femeninos puesto que poseen unas espaldas "demasiado" grandes, algo que, al parecer, tan sólo es propio del género masculino. Otro ejemplo es el de la fuerza, una característica atribuida casi en 
exclusiva a los hombres; las mujeres pueden estar definidas, pero nunca desarrollar demasiado su musculatura.

Estos modelos, estos cánones estéticos forman parte del imaginario social, difundido y mantenido por los medios de comunicación. Unos modelos que han calado en la población general y también en las niñas, las cuales, en su mayoría se niegan a practicar deportes que suponen el desarrollo de su musculatura. De hecho, el Consejo Superior de Deportes (2013) destacó que los estereotipos influyen sobre los tipos de deportes en los que las mujeres más probablemente participen. No solamente se etiquetan los deportes como masculinos o femeninos, las deportistas también pueden ser sujeto de ser etiquetadas y estereotipadas bien como masculinas (posiblemente lesbianas) o femeninas (conforme al ideal). A este respecto, se señala como consecuencia la tendencia de algunas niñas a evitar ciertos deportes por temor a ser percibidas como poco femeninas o lesbianas, y de algunos padres que desalientan a sus hijas ante la práctica deportiva. En última instancia, la homofobia sí aumenta las tasas de deserción entre las niñas adolescentes y las mujeres de participar o de sobresalir en el deporte.

Según el estudio "Mujer, deporte y comunicación: la periodista deportiva y su acceso al ejercicio profesional de la actividad":

Toda la evidencia teórica y empírica demuestra que las diferencias que conducen a mujeres y hombres a practicar deporte responden más a elementos culturales que biológicos. La falta de referentes o ídolos es uno de los escollos que encuentra el fomento de la práctica deportiva femenina. La televisión puede y debe contribuir a que se alcancen modelos deportivos no discriminatorios. Sin embargo, partimos de la tesis de que, a pesar del significativo aumento en la participación de la mujer en el deporte y de todos los esfuerzos e iniciativas abordados, los medios de comunicación siguen ofreciendo una imagen minoritaria de la mujer deportista, siendo en algunos casos una imagen tan difusa que es cercana a la invisibilidad (Vega, R., 2012).

Como se ha señalado anteriormente, los medios de comunicación son de gran relevancia en este aspecto puesto que se encargan de reforzar y afianzar estos estereotipos de género. A ello se une la casi inexistente representación de las mujeres deportistas en sus páginas o en sus programas y en el caso de aparecer, no son sus méritos deportivos sino sus rasgos físicos, o la vida personal, lo más se comentado.

Aunque cada vez es más frecuente que las mujeres se dediquen a la práctica profesional de algún deporte y además destaquen en ellos, sin embargo, los medios suelen hacer invisibles estos logros, apenas aparecen en televisión, no hay publicación de noticias en los periódicos de tirada impresa, ni tampoco se comenta en la radio. La consecuencia de ello es doble. Por un lado, se priva a la sociedad en general, y en concreto a las niñas y a las mujeres, de referentes que fomenten la práctica de un deporte; por otro, se sigue invisibilizando a las 
mujeres al silenciar sus trayectorias, triunfos, logros, etc., ante la población. Sirva como ejemplo la escasa atención prestada por los medios a la selección femenina de fútbol español que, si bien no ocupa los primeros puestos del ranking, está ahí. Sin embargo, las noticias sobre esta selección, aun tratándose del deporte al que más tiempo se le dedica, no admiten comparación con la selección de fútbol masculina, ya que prácticamente son inexistentes, a excepción de alguna breve mención en algún periódico digital. Del mismo modo, y dentro del mismo campo, cabe destacar lo que sucede con el equipo de fútbol femenino Athletic Club que actualmente se encuentra a la cabeza de la liga de $1^{a}$ División Femenina y tras la victoria contra el Atlético de Madrid, el entrenador Joseba Agirre se vio en la obligación de suspender la rueda de prensa porque ningún medio de comunicación fue a cubrirla, tal y como recoge la noticia eldiario.es, el 28 de mayo de 2016.

José Luis Rojas (2010) realiza una distinción de las características que poseen, o más bien, a las que son sometidas las mujeres en el entorno deportivo. Primero, la alusión a su vida familiar, la forma que tienen de vestir, etc., particularidades que nada tienen que ver que con su función y que por supuesto, están abordadas con una perspectiva totalmente distinta a la de los hombres. En segundo lugar, las comparaciones y los estereotipos asignados bajo el rol masculino. Constantemente, a las mujeres se las sitúa en un lugar inferior a los hombres. Las marcas, las puntuaciones, etc., las personaliza el hombre y a partir de ahí, las puede hacer o alcanzar la mujer. Además, la mujer aparece subordinada a la "estrella". Esto suele ser bastante común en el caso de los futbolistas. Así, la pareja de un futbolista puede ser una deportista de élite o tener una profesión destacada, sin embargo, siempre será designada como la pareja de. En tercer lugar, la prensa del corazón deportiva, en lugar de mencionar los logros de las deportistas, suele buscar en el cajón de la vida personal. Y cuarto y último, el androcentrismo se hace casi palpable y se lleva a cabo sobre todo por la difusión y divulgación de determinadas marcas que evidentemente contratan a los deportistas masculinos para representarlas. El deporte ya no es sólo símbolo de salud o competitividad, sino que pasa también a poseer un rol de prestigio fomentado y potenciado por las empresas de publicidad y marketing, hasta el punto que, algunos deportistas, ganan más dinero representando a las marcas que con su propia ocupación. Tal y como señala el estudio realizado por el Consejo Audiovisual de Andalucía (2008),

El periodismo en general y el deportivo en particular, han sido responsables, en gran parte, de la creación y de la concesión de este tipo de identidades que más tienen que ver con ídolos y arquetipos, dignos de ser imitados. Y es por eso que, en la actualidad, los deportistas hombres, además de superhéroes deportivos, son referentes sociales a los que la gente sigue desde una edad muy temprana. Sin embargo, las mujeres continúan teniendo un escaso espacio en este entramado social. $\mathrm{Ni}$ 
publicidad, ni marketing, ni logros deportivos, ni imagen referente para la infancia.

Por esta razón, las deportistas de élite, supuestamente las mejores, y a pesar de que cada vez hay más, no son mediáticamente rentables y económicamente tan sólo lo serán si obedecen a un canon estético socialmente dictaminado. Un ejemplo es el anuncio de Cola Cao $0 \%$ en el que la protagonista no es una boxeadora profesional como Jennifer Miranda, por ejemplo, sino una conocida cantante, representante española de Eurovisión 2015, practicando boxeo. (Enlace del anuncio; Cola Cao 0\% - Edurne [Cola Cao]. (8 de febrero de 2016): https://www.youtube.com/watch?v=5HJSL4rpNao)

Además de todo lo mencionado con anterioridad, es necesario destacar la importancia del lenguaje utilizado en este ámbito. Existe una deformación y alteración de la información dada sobre las deportistas en todo lo que respecta a su carrera profesional.

Un ejemplo de lo que señalamos anteriormente es el escrito por Enrique Yunta para el ABC, hablando sobre la tenista Caroline Wozniacki:

La top sin diamantes. Wozniacki, la número uno, adora a Torres, luce modelitos y aún no ha ganado un grande.

Sin que a la moderadora le diera tiempo de pronunciar el formalismo de «preguntas, por favor», Caroline Wozniacki se adelantó a la prensa y soltó un discurso de cinco minutos, topicazos comunes en el mundo del tenis parejos a los de «el fútbol es así», «hoy en día no hay rival pequeño», «somos once contra once». Frases hechas con tan poco mensaje como gracia, nadería, paja que se dice vulgarmente. «Como he oído que siempre digo lo mismo en las ruedas de prensa, contestó antes de que me preguntéis siempre lo mismo», ironiza. Con ustedes, Caroline Wozniacki (11 de julio de 1990, Odense, Dinamarca), número uno del mundo y clasificada ya para los octavos de final del Open de Australia al superar ayer a Dominika Cibulkova (6-4 y 6-3).

Vale esta presentación para conocer al personaje, aparentemente de trato sencillo y confirmado su flirteo permanente con las cámaras, regalando sonrisas siempre que puede por los pasillos del Rod Laver Arena... (ABC, 22 de enero de 2011)

Para finalizar este apartado hemos de señalar que, el panorama descrito con anterioridad, dista mucho de lo recogido y amparado por la (Ley Orgánica 3/2007, de 22 de marzo, para la Igualdad Efectiva de Hombres y Mujeres) en el artículo 29 punto 1 y 2 establece:

1. Todos los programas públicos de desarrollo del deporte incorporarán la efectiva consideración del principio de igualdad real y efectiva entre mujeres y hombres en su diseño y ejecución.

2. El Gobierno promoverá el deporte femenino y favorecerá la efectiva apertura de las disciplinas deportivas a las mujeres, mediante el 
desarrollo de programas específicos en todas las etapas de la vida y en todos los niveles, incluidos los de responsabilidad y decisión.

\section{METODOLOGÍA}

El objetivo de esta investigación es analizar el tratamiento que la prensa deportiva española realiza del deporte femenino y de las mujeres deportistas. Se parte del supuesto de que dicho tratamiento puede llegar a suponer un freno o una limitación para los avances de igualdad de género, en el ámbito del deporte primero, y después en la sociedad en general.

En esta investigación se parte de las siguientes hipótesis:

- Los periódicos apenas prestan atención a los logros deportivos alcanzados por las deportistas.

- La prensa deportiva continúa utilizando estereotipos femeninos tradicionales para referirse al deporte femenino y a las mujeres deportistas.

- Los periódicos realizan una selección de noticias deportivas en función del deporte. Es decir, recogen noticias sobre deportes considerados tradicionalmente femeninos como puede ser la gimnasia rítmica, la natación sincronizada, patinaje etc., y relegan aquellas otras noticias sobre deportes considerados masculinos.

Para cumplir con los objetivos propuestos y demostrar las hipótesis de partida se realizará un análisis de las noticias sobre el deporte femenino mostradas por los cuatro periódicos deportivos españoles de mayor tirada según el Estudio General de Medios (octubre de 2015 - mayo de 2016): As, Marca, Mundo Deportivo y Sport. Para ello, a través de las redes sociales como Facebook, Twitter, webs oficiales como las de las diferentes federaciones o las de las propias deportistas españolas, se obtendrán todos los logros obtenidos por éstas y a partir de ahí, se verá qué noticias son recogidas por estos cuatro periódicos y cuáles no. Se analizará también el contenido de las noticias para descubrir el trato que reciben las mujeres deportistas y el deporte femenino en general.

Por tanto, se pretende, en primer lugar, examinar qué noticias sobre las consecuciones deportivas femeninas consiguen ser publicadas. $\mathrm{Y}$ en segundo, analizar las expresiones o los modelos estereotipados que se utilizan para referirse a las cualidades, conductas, resultados, etc.; observar y advertir si existe algún sesgo de género.

El análisis se dividirá en dos partes. Primero, se realizará una búsqueda y localización de los logros y las fechas concretas en las que tuvieron lugar. En la segunda, se buscará en los periódicos deportivos (As, Marca, Mundo Deportivo y Sport) si dichas noticias aparecen o no. El periodo que se ha escogido para 
realizar el seguimiento ha sido de un año; del 1 de febrero de 2015, al 1 de febrero de 2016.

Durante el período de tiempo observado, los periódicos han publicado un total de 127 noticias en las que se menciona a deportistas ya sea con un papel protagonista o secundarias, tanto en equipo, como la selección española, o de carácter individual. Del total del universo se ha extraído, por medio de un muestreo aleatorio estratificado (en función del deporte de que se trata), un total de 62 noticias. Para el análisis de contenido se ha utilizado el programa ATLAS.ti; con ello se permitirá visualizar los posibles sesgos de género y así poder sacar conclusiones de la realidad observada a través de las relaciones (redes) establecidas entre los distintos datos y categorías (Alaminos, Francés, Penalva y Santacreu 2015:127).

En el primer nivel, en el textual, lo que se pretende realizar es la codificación de las distintas noticias localizadas en los cuatro periódicos, haciendo anotaciones y aclaraciones sobre lo que se quiere señalar.

Los códigos con los que se va a trabajar en dicho escrutinio de los artículos son:

- Periódico:

Nombre del periódico.

- Fecha:

Fecha en la que se realiza el acto deportivo.

- Tipo de noticia:

Procedencia de la noticia; quién la escribe. Editorial, Agencia o periodista.

- Fotografía:

Si el artículo posee o no una fotografía del evento deportivo.

- Identificación de las deportistas:

Nombre y deporte que practican las deportistas españolas que se quieren localizar en la prensa deportiva.

- Identidad de las deportistas:

Conjunto de rasgos, atributos y características individuales para distinguir a la o las deportistas.

- Papel protagonista/secundario:

Papel que desempeña la deportista en la noticia; principal ocupando el mayor contenido o, por lo contrario, de manera secundaria con una leve pincelada acerca de la actividad que ha realizado.

- Vida sentimental:

Todo lo que conlleve una explicación al margen de la vida deportiva y que tenga que ver con la condición sexual, estado civil, etc. 


\section{- Estereotipos:}

Localizar en las noticias posibles roles o características sociales y culturales, asociadas al sexo.

- Vida cotidiana:

Todo lo que conlleve una explicación al margen de la vida deportiva y que tenga que ver con estudios, viajes, etc.

- Contenido:

Resumen del contenido de la noticia.

- Sexista/no sexista:

Valoración general de la noticia analizando si existe un contenido discriminatorio en función del sexo.

Para que el estudio sea más minucioso, se hizo una división según los códigos más relevantes que se han utilizado para catalogar las noticias halladas. La relación de los códigos que se van a exponer a continuación, viene reflejada en esta red semántica (Gráfico 1) en la que cada uno de ellos posee una vinculación con uno o varios de los otros.

\section{Gráfico 1. Red semántica de códigos}

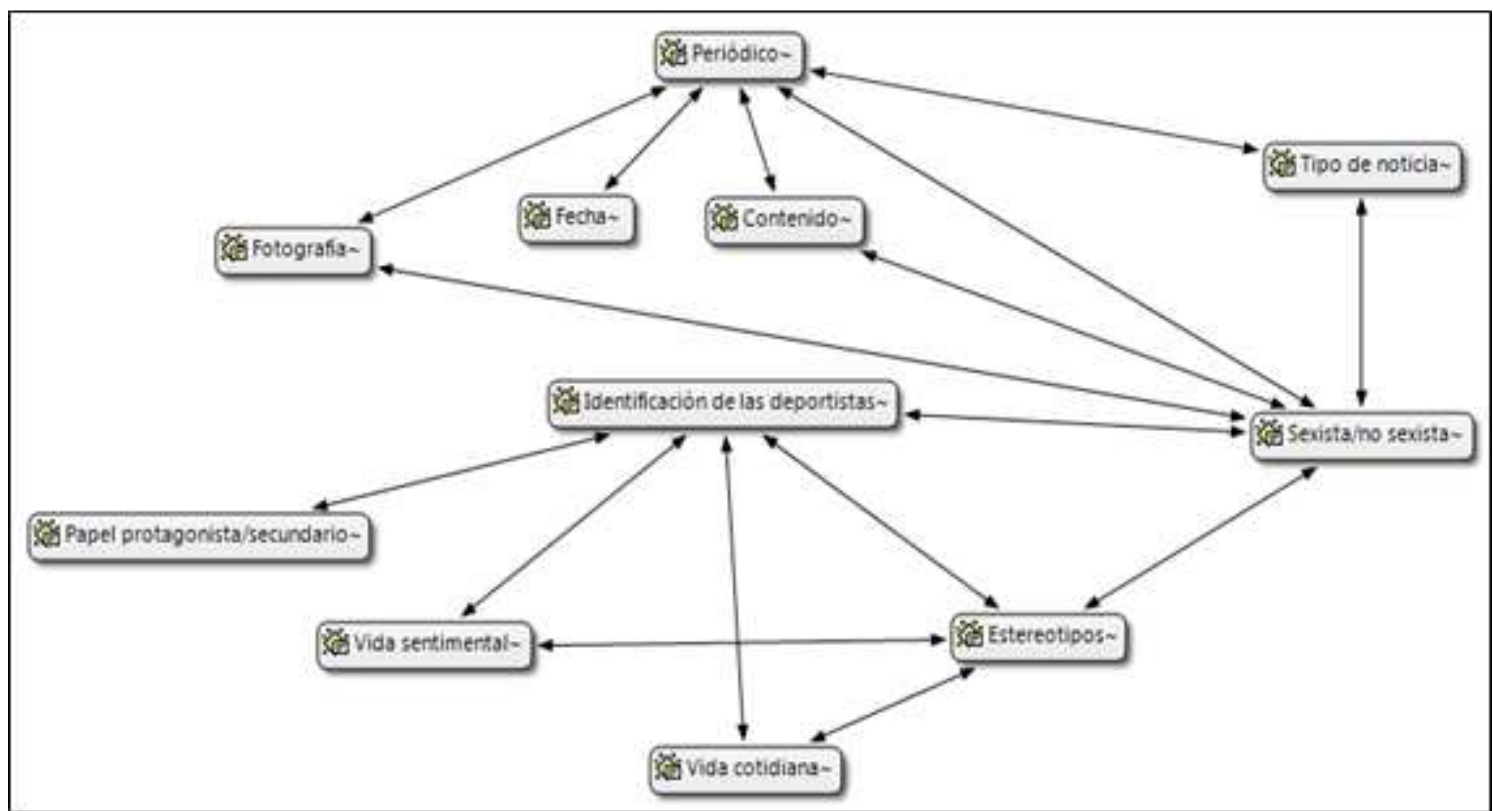

Fuente: Elaboración propia.

Para poder entender mejor esta red semántica, se expone el siguiente ejemplo: el código periódico está vinculado con el código fecha en la que está escrita la noticia, puesto que hay una acotación, a su vez con fotografía para conocer si publica o no imágenes relacionadas; con el tipo de noticia, para conocer de primera mano cuál es la fuente; el contenido es un breve resumen de la noticia y por último, el código con el que se establece si la noticia es o no sexista. 


\section{RESULTADOS}

Como puede observarse en el grafico 2, el tenis es el deporte que tiene un peso mediático mayor, seguido del bádminton. Otros deportes como el rugby o el boxeo, considerados tradicionalmente como masculinos, no aparecen representados en ningún periódico en el periodo de tiempo seleccionado.

El Mundo Deportivo es el periódico que publica el mayor número de noticias sobre deporte femenino y también el que más deportes abarca.

Seguidamente, se expondrán los distintos bloques de análisis según su presencia en los diarios deportivos.

Para poder elaborar una idea del tipo de noticia que se está analizando el primer código que se expone es saber de dónde procede, quién es el autor. Se realiza una catalogación de tres tipos: Agencia, Editorial o periodista.

Gráfico 2. Número de noticias que han sido publicadas según la práctica deportiva

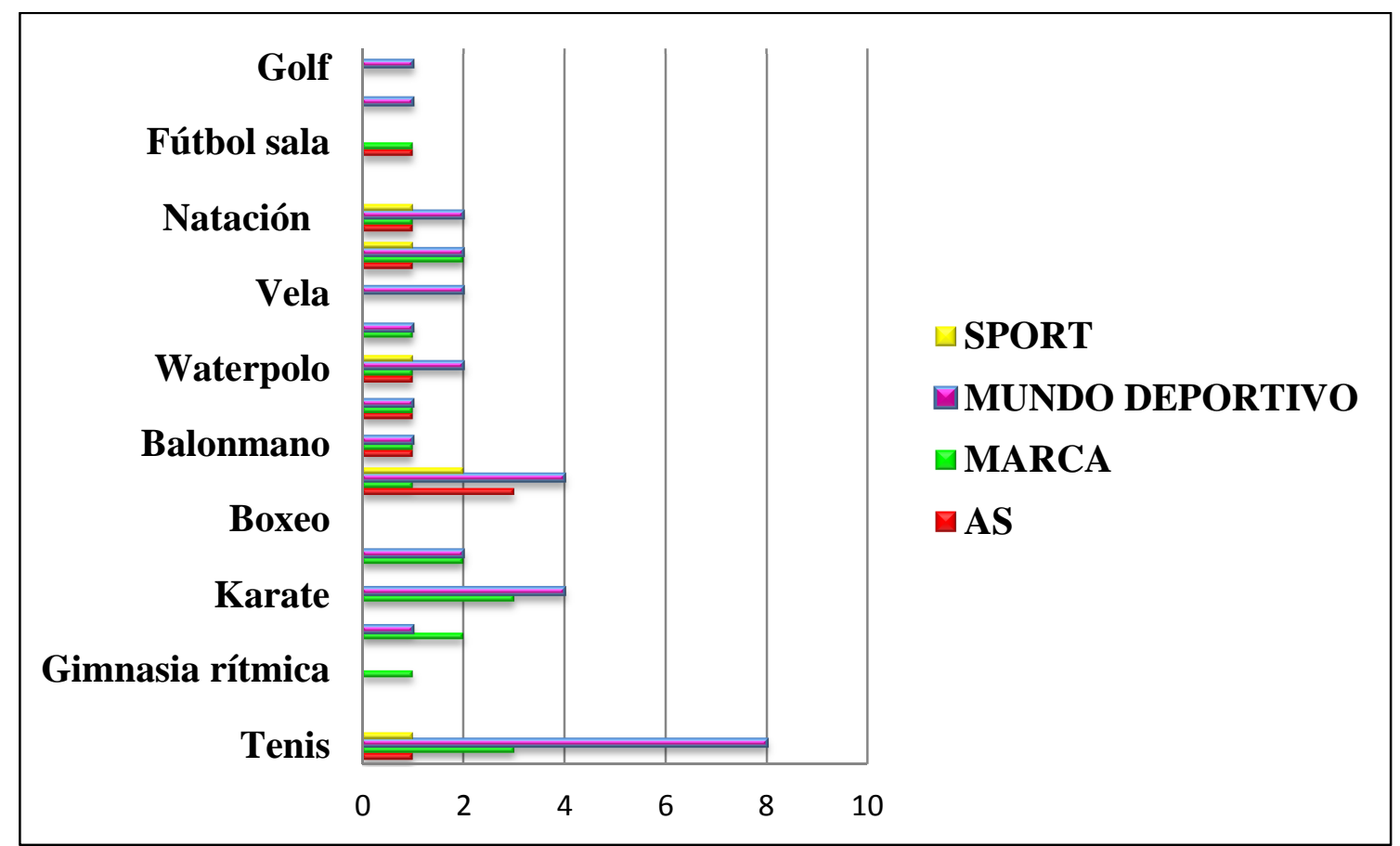

Fuente: Elaboración propia. 
Gráfico 3. Número de noticias por periódico

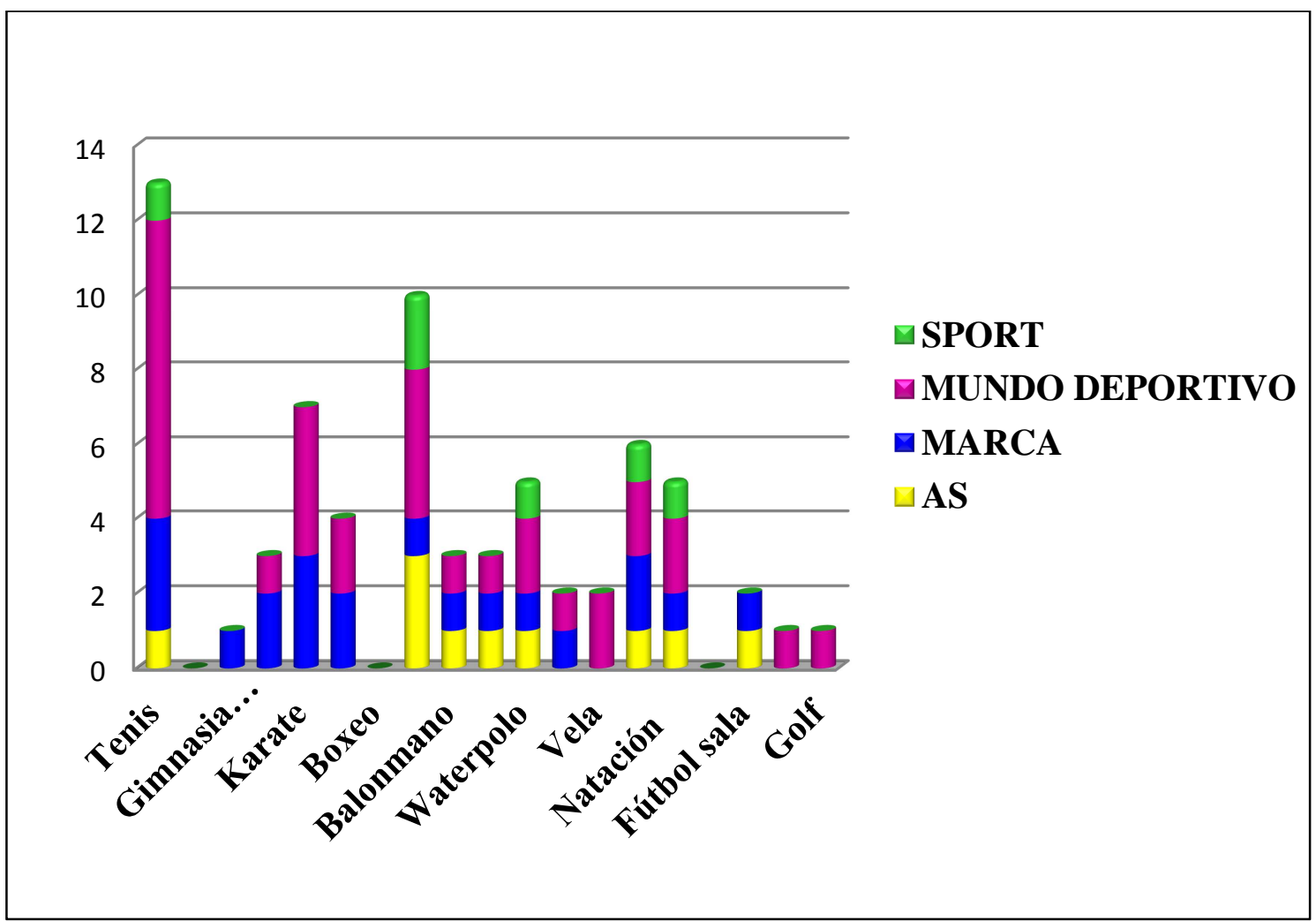

Fuente: Elaboración propia.

Gráfico 4. Tipo de noticia: Agenda/Editorial/Periodista

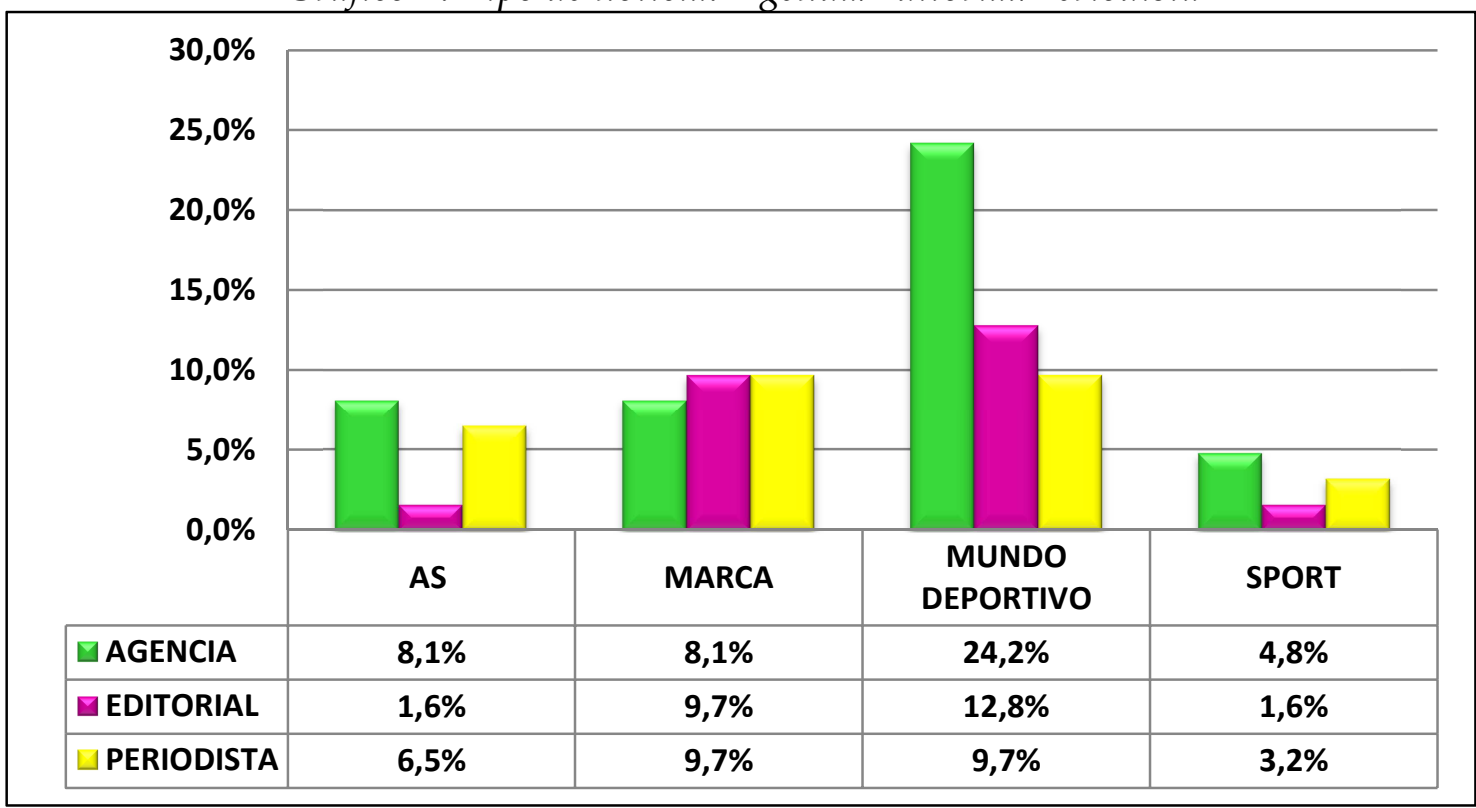

Fuente: Elaboración propia.

Se ha podido comprobar en los cuatro periódicos seleccionados que la mayor parte de las 62 noticias analizadas proceden de Agencia. En concreto, la Agencia EFE es la principal proveedora de noticias deportivas. 
A continuación, lo que se evaluará será la presencia o no de una imagen que detalle el evento deportivo, el logro alcanzado por una o varias deportistas. La presencia de una o varias fotografías, a la hora de exponer una noticia, es realmente importante puesto que es lo primero que le entra por los ojos al lector.

\section{Gráfico 6. Noticias con o sin fotografía que presente el acontecimiento deportivo}

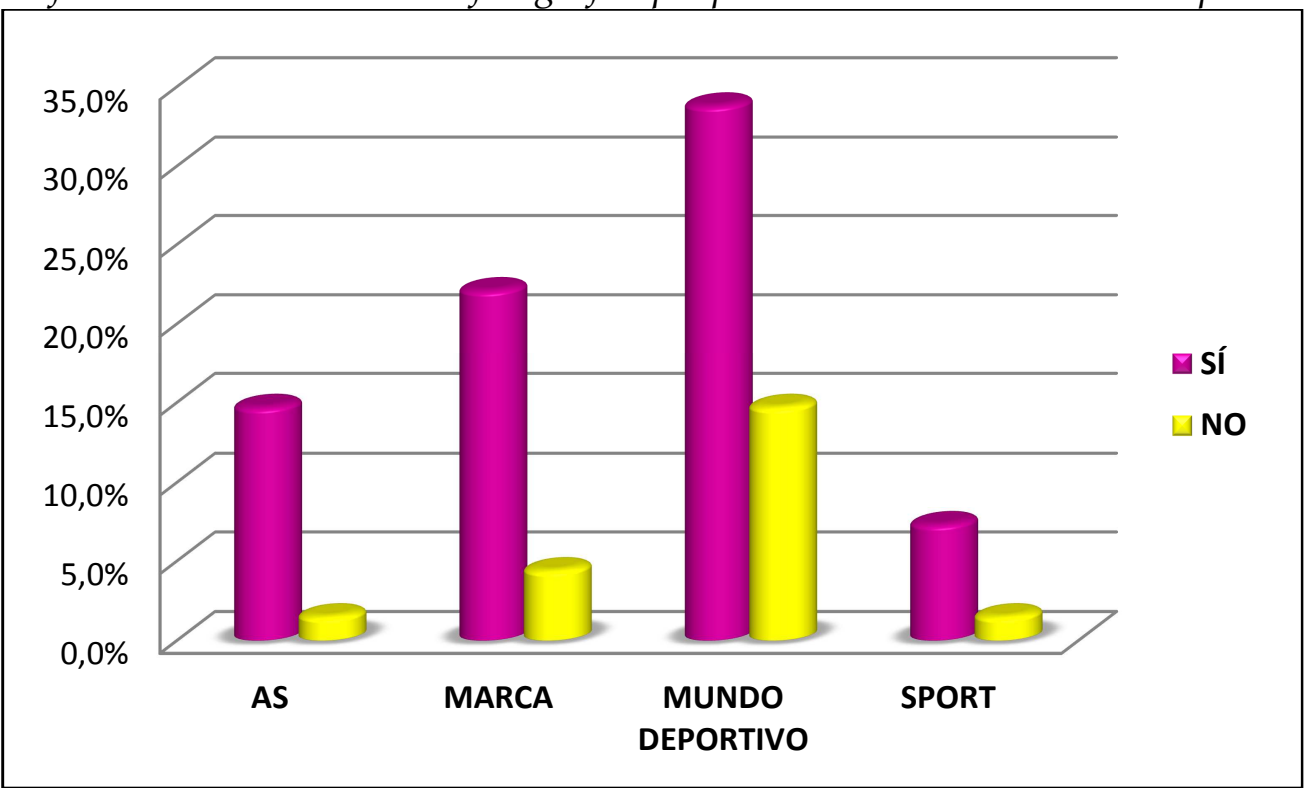

Fuente: Elaboración propia.

Es obvio que el periódico Mundo Deportivo, al ser el que más noticias enfocadas al deporte femenino publica, es el que alcanza los baremos más altos. De 62 noticias se han localizado 68 fotografías.

El acontecimiento deportivo que mayor alcance ha tenido a nivel visual ha sido la final del Campeonato de Wimbledon entre Garbiñe Muguruza y Serena Williams con un total de seis fotografías publicada por el periódico Mundo Deportivo. Y le sigue con dos representaciones gráficas, la entrevista personal realizada a Laia Sanz en el periódico Marca sobre su experiencia en el Dakar.

Con respecto al papel que desempeña la o las deportistas dentro del contenido de la noticia, se observa que en todos los periódicos son mayoría las noticias en las que las mujeres tienen un papel protagonista, con la única excepción del periódico Marca. En este caso, en más de la mitad de las noticias que publican, las deportistas tienen un papel secundario (Gráfico 6). Es frecuente en este periódico publicar noticias sobre deporte masculino y en el cuerpo de la noticia hacer referencia a alguna competición o deportista femenina. 


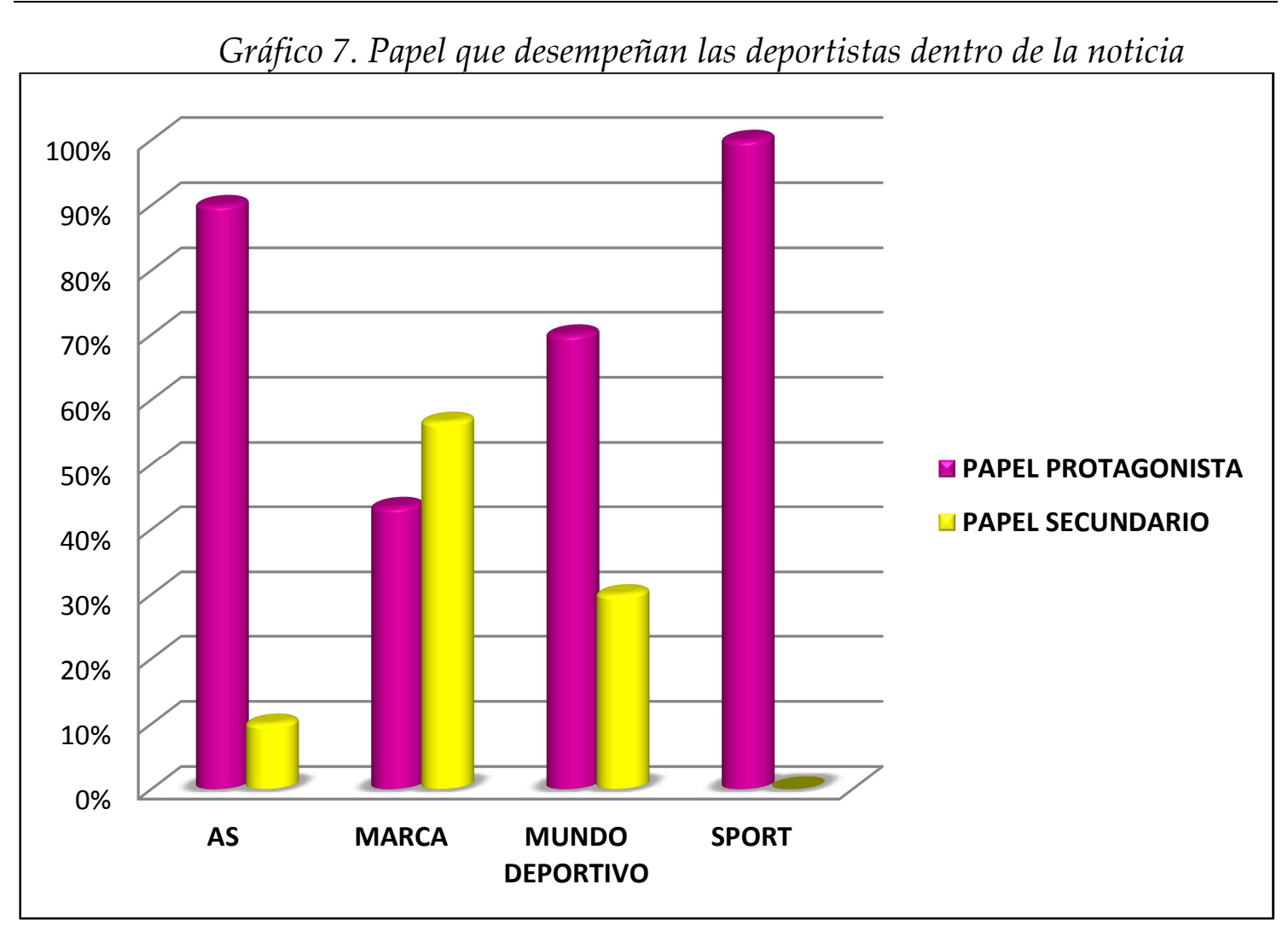

Fuente: Elaboración propia.

Un ejemplo de lo anterior es la noticia de la Agencia EFE publicada por el As en la que se quiere destacar la medalla obtenida por la selección femenina de baloncesto $y$, sin embargo, en lugar de darle el protagonismo a la selección se la da al presidente de la Federación:

El presidente de la Federación Española de Baloncesto (FEB), José Luis Sáez, felicitó a la absoluta femenina después de la conquista este domingo de la medalla de bronce en el Eurobasket de Hungría y Rumanía 2015, ya que volvieron a demostrar "compromiso y competitividad" para mantener a España en el podio con un bronce que "sabe casi a oro". "Era lo que se merecían. Han completado un gran campeonato con todo victorias con una sola derrota. Creo que es un bronce que nos sabe muy bien, nos sabe casi a oro porque han demostrado que siempre dan la talla y se superan", indicó tras la victoria de España (58-74) ante Bielorrusia. Por otro lado, Sáez explicó las cualidades que hacen especiales a las pupilas de Lucas Mondelo, quienes tendrán ahora el objetivo de llegar y pelear los Juegos Olímpicos de Río de Janeiro 2016, después del oro europeo de hace dos años y la plata en el Mundial del año pasado.

"Compromiso, tienen un compromiso y una competitividad... tienen un gen diferente. Por eso hay que seguir apostando, cuando decimos lo de Universo Mujer, no lo decimos por marketing; lo decimos porque lo creemos y porque ellas se lo merecen", explicó orgulloso", tal y como recoge la noticia as.com, el 28 de junio de 2015. 
En esta noticia además se pueden apreciar otros códigos empleados para el análisis como la fotografía en la que siendo ellas las que han conseguido la medalla de bronce, es él, el presidente de la Federación de baloncesto, el que ocupa el lugar central en la fotografía. A lo anterior se añaden juicios de valor como "Era lo que se merecían".

Con los códigos "estereotipos", "vida cotidiana" y "vida sentimental" se pretende identificar en las noticias posibles roles o características sociales y culturales, asociadas al sexo y a su vez, todo lo que conlleve una explicación al margen de la vida deportiva y que tenga que ver con la condición sexual, estado civil, estudios, viajes, etc.

Según el gráfico 8, el periódico que utiliza más estereotipos es el periódico Mundo Deportivo, pero también hay que tener en cuenta, como ya se ha destacado antes, que es el diario que más noticias publica acerca del deporte femenino. Teniendo en cuenta este dato, el As sería el que más veces recurre a este tipo de tópicos para narrar el acto deportivo ejecutado por una deportista.

En lo que respecta a estos códigos, se han podido localizar multitud de ellos en las noticias durante el periodo de tiempo seleccionado para el análisis. Algunos ejemplos que interesa resaltar son los utilizados para referirse a las nadadoras de natación sincronizada como "las sirenas españolas" (Periódico: As / Campeonato del mundo de Kazán), o en la misma disciplina, con Pau Ribes como representante del sexo masculino, que se le adjudica el rol del "macho alfa" asignándole el sobrenombre de "el gallo del corral" (Periódico: Marca). En el ámbito del tenis también se utilizan estereotipos: "Al fin, la chica de Caracas lloró de vuelta a la silla, unas lágrimas de emoción que continuaron a corazón abierto en plena Centre Court de Wimbledon" (Periódico: As / Campeonato de Wimbledon 2015); o haciendo referencia al atuendo utilizado por Garbiñe Muguruza en la final contra Serena Williams: "La multinacional alemana tiene hoy una finalista de Wimbledon, con vestido diseñado por la famosa Stella McCartney, y no es ninguna de esas tres" (Periódico: Marca / Campeonato de Wimbledon 2015).

El último código que se analizó fue el sexismo; si la noticia en su conjunto posee o no esta característica. Es decir, una vez leída la noticia en su totalidad, se realiza una valoración general analizando si existe un contenido discriminatorio en función del sexo.

A este respecto, de 62 noticias analizadas, el cómputo total es de un $26 \%$ de noticias con contenido sexista y un $74 \%$ todo lo contrario, noticias con un contenido objetivo del acto o logro deportivo que se ha llevado a término.

Tal y como se ha venido explicando en el análisis, entre todos los periódicos analizados Mundo Deportivo es el que le dedica más atención al deporte femenino y aunque alguna de las noticias no se salva de tener un sesgo sexista, la mayoría presentan un contenido neutro. 
Gráfico 8. Papel que desempeñan las deportistas dentro de la noticia

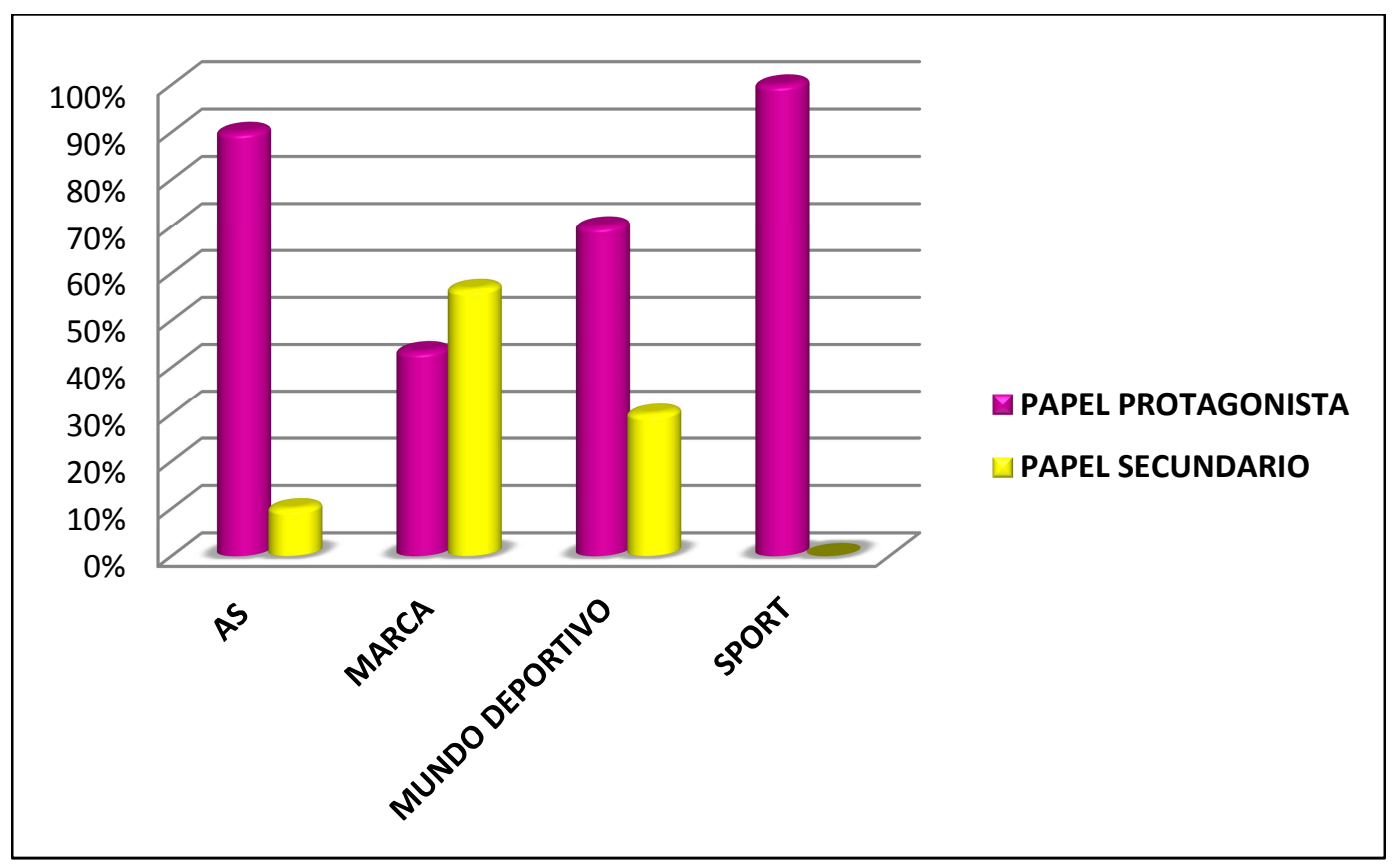

Fuente: Elaboración propia.

Gráfico 9. Noticias sexistas/no sexistas

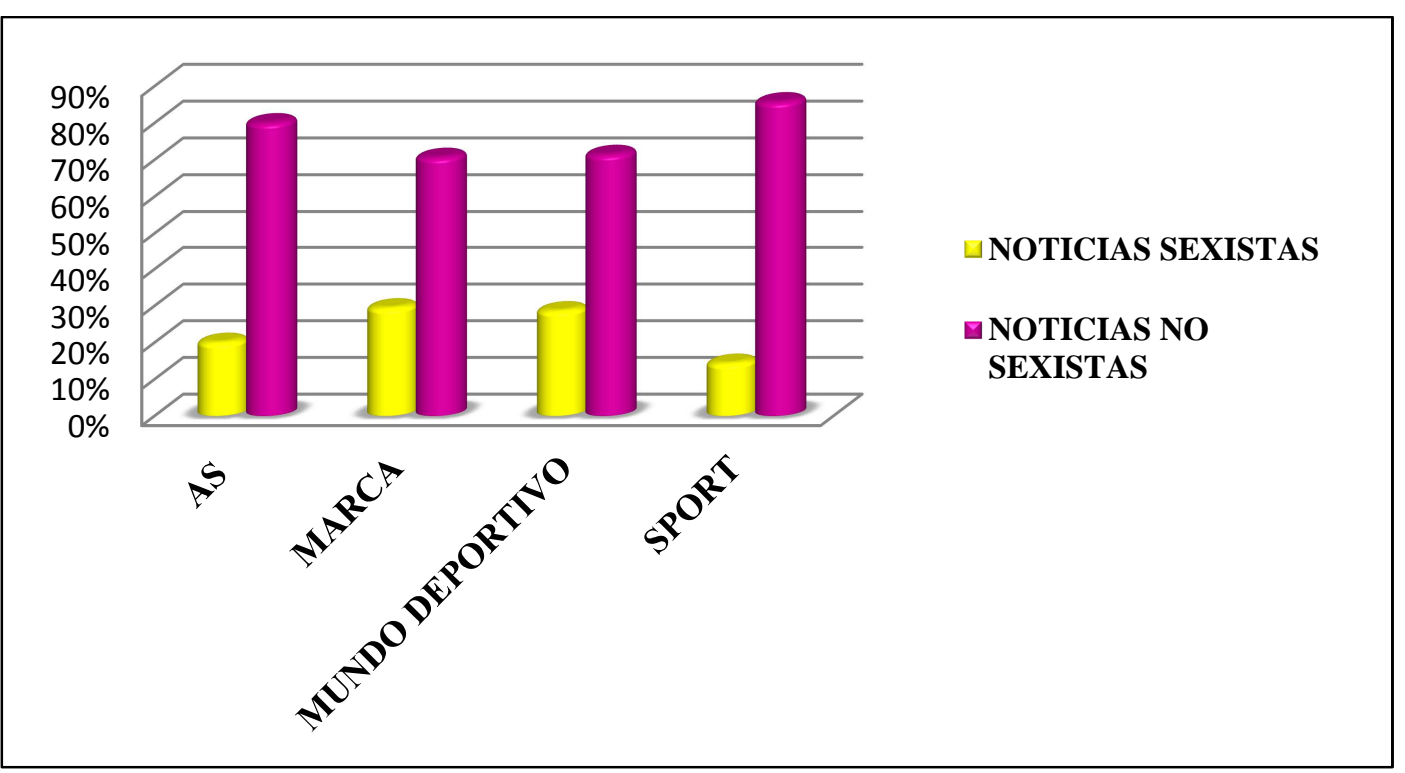

Fuente: Elaboración propia.

\section{CONCLUSIONES}

Como se ha señalado con anterioridad, el objetivo de la investigación es describir la situación actual en lo que respecta a la relación que existe entre la mujer deportista y los medios de comunicación. Todo apuntaba a que con los avances que se han producido en las nuevas tecnologías podría suponer una apertura de puertas a una mayor cantidad de información menos sesgada por el género, pero los datos analizados nos muestran un panorama bastante distinto. 
El marketing ha hecho que los medios de comunicación ofrezcan una información especialmente estereotipada y con tendencia a una importante discriminación sexual, si bien más refinada que en épocas anteriores. La presencia de noticias sobre mujeres deportistas es muy escasa en comparación con las noticias en las que los protagonistas son los hombres. Pero además, el tratamiento que realizan de las noticias reproduce una y otra vez los estereotipos de género tradicionales, en gran medida compartidos por la sociedad, especialmente en lo que atañe a las características físicas que poseen mujeres y hombres.

Los medios de comunicación cosifican a las deportistas. Con frecuencia los deportistas de élite se convierten en modelos publicitarios solicitados por las empresas para la venta de sus productos. No sucede lo mismo en el caso de las deportistas (salvo muy raras excepciones), la escasa presencia de mujeres deportistas en las noticias de los medios de comunicación tiene como consecuencia que apenas son conocidas entre el público, razón por la cual, las deportistas no tienen las mismas oportunidades de atraer a los patrocinadores y las marcas; estos prefieren a modelos o actrices mucho más populares entre los consumidores. A este hecho se le añade una segunda circunstancia, el aspecto físico de las deportistas no es el que quiere ver la audiencia puesto que se da por sentado que esta, la audiencia deportiva, es básicamente masculina y heterosexual, otra razón que explica el que las agencias de publicidad opten por utilizar modelos, actrices que respondan al canon de belleza establecido.

Así pues, el análisis realizado permite corroborar las hipótesis planteadas, esto es, los periódicos, a día de hoy, continúan sin prestar demasiada atención a los logros deportivos alcanzados por mujeres deportistas; los datos expuestos en el análisis dan buena muestra de ello. Así, en el periodo de un año en el que han tenido lugar competiciones de nivel europeo y mundial, tan sólo se han publicado 62 noticias. Pero no sólo esto, sino que también cuando lo hacen, es de manera incompleta puesto que como es sabido, lo primero que le llega al lector es la imagen y en muchas de las noticias no aparece fotografía que represente lo que detalla el artículo. En algunos casos, al aparecer las deportistas como secundarias, la imagen que acompaña la noticia es de algún deportista (hombre). Especialmente en el caso de las publicaciones on-line, escribir una noticia sin complementarla con una imagen, casi se podría decir que carece de sentido.

También se confirma la segunda hipótesis ya que como se ha podido ver con multitud de ejemplos en el apartado de los resultados, la prensa deportiva continúa reproduciendo y difundiendo estereotipos de género que han sido asignados culturalmente y que parecen estar asumidos por los lectores de este tipo de prensa. Finalmente, ratificar también la tercera hipótesis: "Los periódicos realizan una selección de noticias deportivas en función del deporte de que se trate. Es decir, recogen noticias sobre deportes considerados tradicionalmente femeninos como puede ser la gimnasia rítmica, la natación 
sincronizada, patinaje etc., y relegan aquellas otras noticias sobre deportes considerados masculinos". Así, la natación sincronizada o la gimnasia rítmica tienen un peso mediático mucho mayor que el rugby o el boxeo femenino que apenas tienen un hueco en los periódicos.

Otras preguntas que también se plantean son: ¿qué pasaría si cambiase la programación deportiva? Si en el nuevo canal que va a comenzar a emitir en breve, realmente se diese una información equitativa en cuanto al sexo. ¿Realmente tendría un carácter igualitario? ¿Las cámaras enfocarían de la misma manera como se hace con cualquier torneo, campeonato o partido disputado por hombres? ¿Tendría audiencia o bajarían los niveles?

La cobertura de las olimpiadas de Rio 2016 ha sido objeto de denuncias desde muy distintos sectores por el tratamiento sexista que han recibido las deportistas. Referencias continuas al aspecto físico de estas; las comparaciones con las marcas de los deportistas masculinos; las referencias a su edad, estado civil o el número de hijos, han puesto de manifiesto el largo camino que queda aún por recorrer para valorar los logros de los deportistas, independientemente de su género.

Según Engel (1994), la socialización en el deporte se convierte en una confrontación entre sexos puesto que, dentro de los rasgos conductuales, los masculinos van a estar encaminados hacia el liderazgo o la competitividad que son totalmente contrarios al rol sexual de las mujeres. Por lo que parece que existe una incompatibilidad entre la implicación deportiva y la feminidad, sobre todo en la etapa de la adolescencia donde parece ser que el vínculo que existe entre las chicas y su feminidad es bastante estrecho. 


\section{BIBLIOGRAFÍA}

Bach Arús, M. et al. (2000). El sexo de la noticia. Barcelona: Icaria.

Centro de Investigaciones Sociológicas (2010). Hábitos deportivos en España IV. Estudio №. 2833. Recuperado el 4 de mayo de 2016 desde: http://www.cis.es/cis/opencm/ES/1_encuestas/estudios/ver.jsp?estudio=10844

Cola Cao (8 de febrero de 2016). Cola Cao 0\% - Edurne [Archivo de vídeo]. Recuperado el 3 de abril de 2016 desde: https://www.youtube.com/watch?v=5HJSL4rpNao

Consejo Audiovisual de Andalucía (2008). Estudio sobre Género y Deporte en Televisión [versión electrónica]. Sevilla: Consejo Audiovisual de Andalucía. Recuperado el 29 de marzo de 2016 desde: http://www.consejoaudiovisualdeandalucia.es/sites/default/files/publicaciones/ estudio_sobre_gxnero_y_deporte_en_televisixn_2008.pdf.

Consejo Superior de Deportes (CSD) (2010). Hábitos deportivos en España (IV). Centro de investigaciones sociológicas (CIS), $\mathrm{n}^{\circ}$ 2.833. Recuperado el 31 de marzo de $2016 \quad$ desde: http://www.cis.es/cis/export/sites/default/Archivos/Marginales/2820_2839/2833/Es2833.pdf

Consejo Superior de Deportes (CSD) (2013). Deporte y mujeres en los medios de comunicación. Sugerencias y recomendaciones. Plan integral para la actividad física y el deporte + Actividad física, deporte y mujer. Recuperado el 2 de mayo de 2016 desde: $\quad$ https://www.um.es/estructura/unidades/uigualdad/recursos/2013/consejo-superior-deportes.pdf

DeFleur y S.Ball (1982). Teorías de la comunicación de masas. Barcelona: Paidós.

Dervin, B. (1987). "The potential contribution of feminist scholarship to the field of communication", Journal of Communication, Autumn, pp. 107-120.

Engel, A. (1994). Sex roles and gender stereotyping in young women's participation in sport. Sage Journals. Feminism and Psychology, 4, 439-448. Recuperado el 4 de mayo de 2016 desde: http://fap.sagepub.com/content/4/3/439

Espinar, E., Frau, C., González, Mạ J. y Martínez, R. (2006). Introducción a la Sociología de la comunicación. Publicaciones de la Universidad de Alicante.

Gallego Noche, B. (2009). La influencia de los medios de comunicación en el desarrollo de la alta competencia motriz. Wanceulen: Educación Física Digital, 1(5), 35-48. Recuperado el 1 de abril de 2016 desde: http://rabida.uhu.es/dspace/bitstream/handle/10272/3319/b15541174.pdf?sequen ce $=1$ 
Kosicki, G. M. (1993). Problems and opportunities in agenda-setting research. Journal of Communication, 43 (2), 117.

Ley Orgánica 3/2007, de 22 de marzo, para la igualdad efectiva de hombres y mujeres, artículo 29, España, 22 de marzo de 2007. Recuperado el 12 de abril de 2016 desde: https:/www.boe.es/boe/dias/2007/03/23/pdfs/A12611-12645.pdf

Lippman, W. (1922). Public. Opinion. Nueva York. Macmillan, 1922 (trad. Cast.: La opinión pública. San Lorenzo de El Escorial, Cuadernos de Langre, Madrid, 2003).

López Villar, C. (2008). Una visión feminista de la investigación en las ciencias de la actividad física y el deporte. Ponencia llevada a cabo en el IV Congreso Internacional y XXV Nacional de Educación Física, Córdoba, España. Recuperado el 2 de abril de 2016 desde: http://www.uco.es/IVCongresoInternacionalEducacionFisica/congreso/Docume ntos/001-204-491-008-001.html.

Lucas Marín, Antonio, Carmen García Galera y José Antonio Ruiz San Román (1999). Sociología de la Comunicación. Madrid: Trotta.

MacKuen, M. B. (1981). Social communication and the mass policy agenda en More than news: media power in public affairs. MacKuen, M. B. y Coombs, S. L. Beverly Hills, Ca: Sage Publications.

Oyanedel Avilés, R. (2008). Percepción de las mujeres sobre la imagen femenina en la pantalla de televisión abierta (Tesis de pregrado). Universidad Academia de Humanismo Cristiano. Facultad de Sociología. Santiago.

Papí Gálvez, N. (2004). Conciliación de la vida familiar y laboral en la prensa diaria de la Comunidad Valenciana: "el punto de vista" de las mujeres (Tesis doctoral). Universidad de Alicante. Dpto. Sociología II. Alicante.

Pedraza Bucio, C. I. (2012). Mujeres en el periodismo deportivo: reflexiones para comprender la transgresión desde la práctica discursiva de las reporteras de deportes. Derecho a comunicar, 1(4), 46-69. Recuperado el 2 de abril de 2016 desde: http://132.248.9.34/hevila/Derechoacomunicar/2012/no4/4.pdf.

Penalva Verdú, C., Alaminos Chica, A., Francés García, F.J., Santacreu Fernández, Ó. (2015). La investigación cualitativa: técnicas de investigación y análisis con Atlas.ti. Cuenca, Ecuador: PYDLOS Ediciones.

Pérez., G. (1994). Investigación Cualitativa: Retos e interrogantes. Madrid: La Muralla.

Rojas Torrijos, J. L. (2010). La construcción de las noticias deportivas desde una mirada androcéntrica. De la invisibilidad a los estereotipos de la mujer deportista. Revista de comunicación Vivat Academia, (113), 1-15. Recuperado el 1 
de abril de 2016 desde: http://pendientedemigracion.ucm.es/info/vivataca/numeros/n113/PDFs/Rojas.p df.

Taylor, S. y Bogdan, R. (1986), Introducción a los métodos cualitativos de investigación. Buenos Aires: Paidós.

Vega, R. (2012). Mujer, deporte y comunicación: la periodista deportiva y su acceso al ejercicio profesional de la actividad. DDxt-e Revista Andaluza de Documentación sobre el Deporte, $n^{\underline{0}}$ 4. Recuperado el 6 de mayo de 2016 desde: http://www.juntadeandalucia.es/cultura/web/html/sites/consejeria/iad/Galerias/ adjuntos/ddxt-e_4/DDxt-e_004_Textos_02.pdf

Venegas Medina, M. (2010). La maldición de ser niña. Estructuralismo, postestructuralismo y teoría de la práctica en género y sexualidad. Papers, 95/1, 139-156. Recuperado el 1 de abril de 2016 desde: https://dd.uab.cat/pub/papers/02102862v95n1/02102862v95n1p139.pdf

Yunta, E., (22 de enero de 2011). La top sin diamantes. Wozniacki, la número uno, adora a Torres, luce modelitos y aún no ha ganado un grande. $A B C$. Recuperado el 2 de mayo de 2016 desde: http://www.abc.es/20110122/deportestenis/abcp-diamantes-20110122.html

ELENA LÓPEZ ALBALÁ es graduada en Sociología por la Universidad Complutense de Madrid y la Universidad de Alicante. En la actualidad está realizando un Máster de Gestión de Riesgos Naturales además de colaborar con la Universidad de Alicante en proyectos de investigación con una Beca de Colaboración.

Recibido: 05/09/2016

Aceptado: 30/11/2016 